\title{
Discussion Paper English Language Learners and Special Education in Ontario Schools
}

\author{
Stacey Robert-Tobin ${ }^{1, *}$ \\ ${ }^{1}$ Academic Coordinator - General Arts \& Sciences, St. Clair College, Canada \\ *Correspondence: Academic Coordinator - General Arts \& Sciences, St. Clair College, Canada
}

Received: November 5, 2016

Accepted: November 15, 2016 Online Published: January 25, 2017

doi:10.5430/ijelt.v4n1p32

URL: http://dx.doi.org/10.5430/ijelt.v4n1p32

\section{Introduction}

Canada is a country with a high level of diversity and an official policy of multiculturalism. Ontario schools are filled with students from all races, religions, and ethnic backgrounds. This creates an environment that is dynamic, unique, and rich in culture. However, cultural diversity can present several challenges for educators when trying to balance between the specific needs of each student and the available resources to support those needs.

Each year Canada welcomes thousands of new immigrants from all over the world. As a strong member of the global community it has also developed an international partnership with the United Nations, accepting several forced immigrants each year. In fact, Canada grants refugee status to over 14, 000 people per year with an estimated arrival of 400,000 refugees since World War II (Kaprielian-Churchill, 1996).

Of the large portion of refugees and new arrived immigrants that Canada accepts per year, a significant number of them are young children and adolescents. This presents several challenges to the education system when dealing with a diverse student population. The Canadian government has taken relatively progressive steps to deal with the integration of newcomers by creating programs to assist with relocation and adjustment to Canadian culture.

The rapid influx of newly arrived immigrants in Canada has also led to an increase in the demand for courses offering educational training in the English language; which has now become the most widely used language in the world. In many countries the proportion of students learning English as their second language is increasing dramatically and presenting educators with greater challenges (Wolley, 2010). In Canada, English as a Second Language is now provided in a number of educational institutions at the elementary and secondary level. The primary purpose of these programs is to assist students whose first language is something other than English.

The needs of English-language learners are both diverse and unique to the individual. Assessing the specific needs of ELL students can often be a daunting task. Even more difficult is when an English language learner also has a potential learning disability. In recent years there have been a growing number of ELL students that are being recognized as also having a learning disability. This creates a demand for resources and support that are often insufficient for the needs of English language learners. Additionally, many schools find it challenging to distinguish language differences from disability as the source of academic difficulties for ELLs (McCardle, Mele-McCarthy, Cutting \& Leos, 2005).

English language learners and students with learning disabilities face unique educational challenges. Combined together they can be overwhelming for any student to deal with. Children who suffer from learning disabilities generally have problems with phonetics. ELL's can read the words in their language but struggle significantly when attempting to do so in English. This inability to speak and write in English can dramatically affect an ELL's academic success. When a child is a potential ELL with LD's it makes things even more complex.

This discussion paper will explore some of the underlying issues related to English language learners and learning disabilities. Grounded in relevant and related literature pertaining to diverse classrooms, it will examine factors such as identification, assessment, and support for English language learners with learning disabilities. More specifically, this paper will attempt to address the question:

- What are some underlying issues associated with special education identification and English language learners? 


\section{Positionality of the Researcher}

I have always been quite passionate about issues related to social justice. More specifically, my research has been focused on the challenges faced by minority students in Canada; appearing to be far greater than those faced by native born students. For several years I have taught and worked closely with a variety of minority students in the elementary, secondary, and post-secondary divisions. Many of these students are forced immigrants formally known as refugees. I have bared witness to several of the challenges faced by these students and other minorities in the education system. Some of these students have shared with me their stories of personal hardship and struggle. Many of these experiences are also quite telling about the realities of our Canadian education system.

I have personally worked with a number of students who I felt were either misdiagnosed or mistreated due to language barriers or learning difficulties. As both a social justice advocate and an educator I find this rather disheartening. The school system maintains and reflects the norms of the dominant culture and this profoundly affects the way that schools operate. "These norms have maintained power and privilege for certain groups of people and marginalize others based on race, class, disability, sexual orientation, language, gender, and family structure (Theoharis, 2007). Schools are therefore, challenged in maintaining an environment that is fair and equitable for all.

\section{What are the Issues?}

The goal of any educational institution should be to provide, maintain, and consistently improve the educational experiences of every student. As an agent of socialization, the education system plays a significant role in the ongoing development of our Canadian youth. The ultimate goal should be to eliminate the historical norms commonly found within our education system; that is, those which benefit some students while disproportionally providing education to others. "These norms have maintained power and privilege for certain groups of people and marginalized students based on race, class, disability, sexual orientation, language, gender, family structure, and neighbourhood" (Theoharis, 2007, p. 18).

Issues of inequality surround the educational lives of many English language learners with learning disabilities. An English language learner can be defined as a student whose native language is not English, and whom has difficulties in speaking, reading, writing, or understanding the English language without support (Chu \& Flores, 2011).

Student-teacher relations are just one example of where these inequalities exist. If teachers are not experienced in diverse cultural settings than it may be difficult for them to understand and relate to the ESL students in their class (Wolley, 2010). Some educators also presume to know the needs of their students. Such presuming-to-know can lead to a distinct lack of compassion for students from diverse and complicated backgrounds. Educators can frequently make assumptions about socially diverse environments based on cultural biases. These biased notions of cultural difference are linked to narrow conceptions of race, ethnicity, language, and class,” (Cooper, 2009, p. 716).

Perhaps one of the biggest problems in the education system is the misunderstandings that occur between teachers, parents, and students in diverse environments (McKenzie \& Scheurich, 2004). Communication and relationship building is crucial to the success of ELL's with LD's. "More frequently than not, failures in communication lie at the heart of problems in organization, goal setting, productivity and evaluation" (Gorton, \& Snowden, 2012, p. 101). False assumptions about home life and education backgrounds can frequently lead to inappropriate placement.

Identification or a Misdiagnosis?

According to the Individuals with Disabilities Act, learning disability refers to a disorder in one or more basic psychological processes involved in understanding or using language, spoken or written, that may manifest itself in an imperfect ability to listen, think, speak, read, write, spell, or do mathematical calculations (Chu \& Flores, 2011). Identifying whether an English language learners also has a learning disabilities can be quite challenging. Several factors such as cultural variables, family background, and previous education must all be taken into consideration. Currently, the identification of English language learners with learning disabilities is hampered by a lack of theory and standards that describe the normal course of language and literacy development for English language learners (Wagner, Francis, \& Morris, 2005).

A lack of theory and standards can lead to the misdiagnosis of some students. This is a theme that is frequent in the literature. It has been argued that some students are placed in special education classes based on linguistic, cultural, and socioeconomic factors instead of academic ability. Also problematic is that many teachers have difficulty teasing apart these socioeconomic, linguistic, and cultural characteristics from the psycho educational factors often associated with ELL'S (Wolley, 2010). These factors may influence identification of ELL'S with LD's resulting in 
misdiagnosis and a disproportionate number of English language learners being placed in special education programs (Wolley, 2010).

Students who are culturally linguistically diverse (CLD) represent an increasing number of those identified as English language learners with learning disabilities and evidence suggests that they are not receiving the services and supports they need to be successful in schools (Sullivan, 2011). "The disproportionate representation of CLD students in special education is a long-standing issue first introduced in the literature more than 40 years ago," (Sullivan, 2011, 318).

McCardle, Mele-McCarthy, Cutting, and Leos (2005) argue that ELL students tend to be overrepresented in certain special education categories: Speech-Language Impairment, Mental Retardation, and Emotional Disturbance. Additionally, the percentage of English language learners who receive special education services in urban localities surpasses the national special education percentages for students who speak English as a first language. This causes much concern for the way in which English language learners are being identified as students with LD's and suggests the need for better tools for identification.

\section{Assessment}

Assessment is another theme that is discussed frequently in literature on ELL'S with learning disabilities. Assessment of English language learners can be a complicated and daunting process because there is no one single approach. For example, research has demonstrated that phonological awareness is very important but it is only one of the skills which predict the ability to read successfully (Wolley, 2010). However, relying on a single formal assessment tool such as this is problematic. Furthermore, instruments are often developed based on the needs of native born students, compromised of cultural bias and, therefore, are unlikely to give accurate results for ESL students (Wolley, 2010).

According to Wagner, Francis, and Morris (2005) assessment of English language learners in English can be problematic because individuals may not fully understand the task instructions, even if they have the competence to perform the task in English. Therefore, formal assessments must be conducted and include tests that are understandable to the reader in their native tongue. These formal assessments also involve the parents or guardians of the student. According to the Individuals with Disabilities Education Act, families have the legal rights and responsibilities for being involved in the special education process, including assessment (Chu \& Flores, 2011). Their participation in the assessment process is crucial because they can provide feedback on educational history of their child.

It is important to have diverse methods of evaluation for linguistic diversity. However, administering a non-biased assessment is difficult because English language learners and those with learning disabilities may share many characteristics, such as poor motivation, low self-esteem, and poor oral language skills (Chu \& Flores, 2011). Assessment is also a challenge because of language barriers between stakeholders and confusion of educational background. Curriculums frequently vary from country to country with some educational systems being far less or far more superior than others. These differences make it difficult to know whether a child can sufficiently handle course material or whether they are academically superior to their peers.

\section{Educational Support}

According to Chu \& Flores (2011) ELLs are almost four times more likely to be identified as having language or speech impairments as compared to students who are proficient in English. If this is the case we must question to what extent these students are being supported. Teacher preparedness to both identify and instruct English language learners students with special education needs is also a point of interest. There is concern for a lack of qualified staff to meet the needs of students who are English language learners with learning disabilities. Many schools have reported not having the tools, procedures, or qualified staff to adequately identify and support these students (McCardle, Mele-McCarthy, Cutting \& Leos, 2005).

Qualified staff members frequently work with students in classrooms that are dedicated to English proficiency. Being placed in ESL rooms provides some comfort because the students are surrounded by others like themselves. However, removal from mainstream classrooms can also promote segregation and barriers to language development. Additionally, when general and special educators lack cross-cultural competence or knowledge of linguistic diversity, ELLs are at high risk of over-or underrepresentation in the category of learning disability (Chu \& Flores, 2011). These concerns point to the need for a school system that has developed appropriate assessment, support, and placement procedures for immigrants whose educational backgrounds are often less predictable than those of native born students. 


\section{Implications and Possible Solutions for Improving the Educational Experiences English Language Learners with Learning Disabilities}

In recent years there has been an increase in the amount of literature pertaining to English language learners. However, there is still a need for data pertaining to ELL's with learning disabilities. Some of the studies that have been done suggest that English language learners who have LD's can benefit from phonetic instruction, comprehension strategies, and peer-assisted learning. ELL's can also benefit from sheltered English techniques. These techniques involve the use of visual aids which can assist ELL's in conveying and understanding the meaning behind the words (Sullivan, 2011). More research needs to be done on the effectiveness of these techniques but a strong framework seems to be in place.

The education system must also seek different ways to foster the ability to operate, collaborate, and work in diverse cultural contexts (Daniel, 2007). These are complex and dynamic school environments that require collaborative efforts for success. For example, schools can enhance the overall assessment process by utilizing wider sources of expertise. This whole-school approach minimizes the classroom teacher's over reliance on special educators. Teams consisting of general education and ESL teachers, administrative staff, teacher aides and parents can provide expertise in a number of areas (Wolley, 2010). Social cohesion, reciprocal learning, and open communication are the building blocks to a collaborative school environment. Students cannot receive the education they deserve unless purposeful steps are taken to change schools on their behalf with both equity and justice in mind (Theoharis, 2007).

Parents can also provide valuable information to assist teachers with the process. This is why communication between all stakeholders is crucial to appropriate identification, assessment and placement. Not all English language learners are immigrants. Perhaps, their parents immigrated here and the reason for poor development in the English language is due to child-rearing. Questions pertaining to previous education in English or prior assessments can be easily acquired from the information obtained during a conversation with a child's parents; rather than solely relying on the information gathered during tests. If the child has a history of difficulty with reading and writing in his native language than perhaps this may indicate a learning disability. However, it could indicate that the child received poor instruction in their home country so this must also be considered.

Research initiatives need to be strengthened with a greater focus on acquiring data directly related to learning disabilities within English language learners. These initiatives could also target learning disabilities in general and the normative development of language and literacy from an increasingly diverse set of primary languages (McCardle, Mele-McCarthy, Cutting \& Leos, 2005). Much can be gained from exploring various forms of assessment and testing that more closely reflect the needs of each student.

Lastly, appropriate instruction for ESL learners should include explicit support in language and literacy and access to a curricula associated with high but realistic teacher expectations (Wolley, 2010). This is similar to the well-rounded curricula and ultimate goals of any mainstream classroom in Ontario. It has also been asserted that positive outcomes result when oral and written language are given purposeful meaning in ways that are comprehendible by students (Wolley, 2010). The incorporation of culturally relevant pedagogy would be highly beneficial to English language learners with learning disabilities and should be afforded to them whenever possible.

\section{Conclusion}

It is clear that ELL's face a number of challenges not shared by their fellow peers. Issues that are both social and academic present a real challenge to the education system. Perhaps, one of the greatest problems is that many educators are still quite unaware of the issues discussed in this paper. As a result, these issues will continue to persist unless effective measures are taken to foster change. Research has demonstrated that change can occur but it must be done with transformative knowledge; thereby educating the educators. Teachers need to have an open mind and make every attempt to understand the needs of their students. Communication between parents, teachers, and administrators is also of vital importance to the success of each student. Schools must adopt an environment that practices inclusion rather than exclusion. This is not only morally right but it prevents segregated programs from creating unequal instruction and insufficient levels of education.

The research world is still lacking in literature pertaining to English language learners with learning disabilities. However, there is increasing interest in the phenomenon and the number of studies being produced is rising as well. The quality data that can be derived from such studies is vital to the academic success of our Ontario students. Future research should expand upon some of the issues addressed in this discussion. More specifically, researchers should take a closer look at identification, assessment, and support for ELL's with a special emphasis on primary language and culture. These issues are not only important to the research world but to all teachers, parents, and administrators who 
work and live in diverse climates. The ultimate goal is provide a quality education to all students, regardless of culture or background because education is a right deserved by all.

\section{References}

Chu, S., \& Flores, S. (2011). Assessment of English Language Learners with Learning Disabilities. A Journal of Educational Strategies, Issues and Ideas, 84(6), 244-248. https://doi.org/10.1080/00098655.2011.590550

Cooper, C. (2009). Performing cultural work in demographically changing schools: Implications for expanding transformative leadership frameworks. Educational Administration Quarterly, 45, 694-724. https://doi.org/10.1177/0013161X09341639

Daniel, Y. (2007). Globalization and the social justice agenda for education: Moving from critique to possibilities. A Journal of Educational Research and Practice, 16(2), 12-20.

Gorton, R., Alston, J., \& Snowden, P. (2012). School Leadership and Administration: Important Concepts, Case Studies, \& Simulations(9th ed.). New York: McGraw Hill.

McCardle, P., Mele-McCarthy, J., Cutting, L., \& Leos, K. (2005). Learning Disabilities in English Language Learners: Identifying the Issues. Learning Disabilities Research \& Practice, 20(1), 1-5. https://doi.org/10.1111/j.1540-5826.2005.00114.x

McKenzie, K., \& Scheurich, J. (2004). Equity traps: A useful construct for preparing principals to lead schools that are successful with racially diverse students. Educational Administration Quarterly, 40(5), 601-632. https://doi.org/10.1177/0013161X04268839

Sullivan, A. (2011). Disproportionality in special education identification and placement of English language learners. Exceptional Children, 77(3), 317-334. https://doi.org/10.1177/001440291107700304

Theoharis, G. (2007). Social justice educational leaders and resistance: Toward a theory of social justice leadership. Educational Administration Quarterly, 43(2), 221-258. https://doi.org/10.1177/0013161X06293717

Wagner, R., Francis, D., \& Morris, R. (2005). Identifying English Language Learners with Learning Disabilities: Key Challenges and Possible Approaches. Learning Disabilities Research \& Practice, 20(1), 6-15. https://doi.org/10.1111/j.1540-5826.2005.00115.x

Wolley, G. (2010). Issues in the identification and ongoing assessment of ESL students with reading difficulties for reading intervention. Australian Journal of Learning Difficulties, 15(1), 81-98. https://doi.org/10.1080/19404150903524564

Yau, M. (1996). Refugee students in Toronto schools. Toronto board of education, 15(5), 9-16. 